\title{
The Effectiveness of Multimedia in Education for Special Education (MESE) to Improve Reading Ability and Memorizing for Children with Intellectual Disability
}

\author{
https://doi.org/10.3991/ijet.v13i08.8291 \\ Munir $\left.{ }^{\bowtie}\right)$, Wawan Setiawan, Eddy Prasetyo Nugroho and Jajang Kusnendar \\ Universitas Pendidikan Indonesia, Bandung \\ munir@upi.edu \\ Aji Prasetya Wibawa \\ Universitas Negeri Malang, Malang, Indonesia
}

\begin{abstract}
The difference between learning using one sensory ability (e.g. reading text or hearing or looking at the pictures only) and two or more (e.g. reading text equipped by sound and visualized by animation; and even allows children to get involved directly in the process of learning) was that the low ability in memorizing. MESE (Multimedia in Education for Special Education) was a multimedia application developed for reading for children with intellectual disability. This research aimed to find out MESE effectiveness in learning related to reading skills and memorizing. MESE was very attractive and had interactive ability that provided opportunity to learners for independent study. The method used was SSR (Single Subject Research). The results showed that learning by using MESE application enhanced reading skill and memorizing. The analysis of the student's worksheet of reading ability and memorizing showed positive result though several sessions showed a decline and or a stable.
\end{abstract}

Keywords-multimedia, reading ability; memorising; special education

\section{Introduction}

Based on the result of preliminary study, students with intellectual disability are still having troubles in terms of the ability to read and comprehend the reading contents. Various limitations experienced by children with intellectual disability are the lack of motivation to read, a short memory, an expectation of visual teaching and learning as well as an involvement directly in the learning process. For children with intellectual disability, training sensitivity in learning to be able to respond to the environment, can be obtained through reading, observing, researching, or asking someone [9]. Reading that utilizes either a story or literary work is expected to provide a positive impact in terms of: (1) reading interest, (2) motivation in reading habit, (3) reading comprehension, and (4) knowledge and experience. [6, 15].

Researches show that learning using one sensory ability (reading text, listening and/or looking at pictures only) resulted a low ability in memorizing. Yet, learning 
using two sensory or more (reading text equipped by sound and visualized by animation; even enable children to get involved in learning process) resulted well $[14,17]$. Learning by using visual media will be memorized longer [19]. Sound which relies on hearing is suitable only for information content learning [11]. In order to be memorized longer, a media should be interactive to be likeable by children [13]. Other methods which can extend memory are by observing the speed of learning process and how often the learning process conducted [10].

Besides using multimedia application, reading will be optimal if teachers are creative in using media and have the right approach. The techniques in reading need to be adjusted also with basic competencies, methods, learning approach, and time allocation [16]. Children with intellectual disability will be able to learn faster and memorize longer if various media and sensory (speaking, listening, seeing and sensing) as well as text with the concept of storytelling are used [5]. The aim of this research is to find out whether the application of MESE is able to increase the reading skill and memorizing in children with intellectual disability.

\section{$2 \quad$ Literature Review}

Cognitive theory is a general framework contains some guidelines to improve learning. One of the guidelines explains excessive cognitive risk in learning by using pictures and visual texts. By considering work memory model, the excessive cognitive can be prevented if only text is presented in auditory form instead of visual since picture processing and information are separated [8]. The cognitive theory of multimedia learning also combines concepts to design optimum learning environment [10]. One of the concepts is modality which recommends picture and information presentation through visual hearing instead of text. In most learning process, information or knowledge are gained through eyes and ears. The cognitive theory of multimedia learning states that there are differences in achieving and memorizing learning material through visual and auditory especially in the speed of learning [8]. Time pressure increases the negative influence from the effects of attention division. Students do not have to divide attention in understanding information and knowledge by using auditory media. As for those who use visual media have to divide their attention between text and visuals in the time set. Thus, do not consider the speed of learning to succeed learning using multimedia. Instead, the one should be considered is how to have a strong and longer memory [12]. In other words, media which involves various senses improved and optimized the process of teaching and learning [21].

Reading using multimedia in Special Education emphasis on comprehension, information absorption and impression. Thus, students must have the skills to read Word for Word. As for the speed factor, it depends on the purpose of reading as it involves thinking, reasoning, emotion and attitude of students in accordance with the reading theme. Children with intellectual disability experience "lack of fantasy". Storytelling at the age of 3-7 years old is common for normal children. Their fantasy evolves rapidly through the language. Yet, it is vice versa for children with intellectual disability. Their fantasy cannot be stimulated by a fairytale/story. The fantasy of 
children with intellectual disability attached to concrete circumstances and fixed complexes [20]. Reading for them will consist of words in motions and lips pattern as a substitute for the sounds of vowel, consonant, and intonation [6]. Through reading, they gained experience and insight to interact with their surroundings. The process is not easy of course. Therefore, parent's role to support the program is needed.

Reading skills for children with intellectual disability is different from the normal ones in general. They have limitations in the ability to read and understand the contents. Children with intellectual disability who graduates from elementary school is on stage 9 of the 10 stages. $66 \%$ of the sample of students with intellectual disability age 11 in Indonesia showed that the reading ages are 4 years over the normal ones. Thus, children with intellectual disability experience difficulties in reading; they will be increasingly left behind by their peers who are normal and the material is getting complex also [4]. Therefore, reading for children with intellectual disability needs appropriate media which involves all senses and constant guidance and it should be interactive. These are proven by research result of learning alphabets through auditory media and learning sentences through visual media. [2].

\section{$3 \quad$ Methodology}

The research used SSR (Single Subject Research) method which highlighted a group design focused on data that came from a group of individuals, as research sample. The sample in this research was two children with intellectual disability from Special Education School in Sukabumi. Reading was performed using the approach of storytelling through MESE application to improve the ability to read and understand the contents. Storytelling is a process of knowledge transfer that is usually done to a child through a story that is packed attractively so that children can listen, read or see with the senses they have, in the hope that children focus on capturing the contents of the story as to retell what he/she received with his/her own language. On the Single Subject Research, there were two variables i.e. dependent and independent variable. The dependent variables were reading skills and memory, while the independent variable was storytelling through MESE application.

Learning alphabets would be easier by singing or hearing sounds since analyzing would not be needed. As for learning sentences, visual was needed in order to analyze alphabets series in creating sentences. Besides, visual contributed the role to understand the sentences as well as the content. MESE not only included auditory and visual media but also animation as well as interactive media. The results showed that learning by using MESE application enhanced reading skill and memorizing. The analysis of the student's worksheet of reading ability and memorizing showed positive result though several sessions showed a decline and or a stable.

Research procedure was designed in two phases namely Baseline (A), to see the ability as behavior obtained from results of a pretest, learning, and posttest of 4 sessions. The second stage is interference (B), to see the ability in reading and measure memory by using MESE application during session 5, 6, 7 and 8. This research focused on the data acquisition and processing to measure the ability to read and 
memory of children with intellectual disability through MESE application. The subjects in this study were two children - a female (F) and a male (M). Both were chosen since they had a weak reading skills which not yet reached the minimum score specified (6.0). Therefore, interference was needed so that both will understand the content better.

\section{$4 \quad$ Results And Discussion}

The data obtained were shown in Table 1. This table showed the number of correct answer and final score during session 1, 2, 3 and 4 (baseline) as well as 5, 6, 7 and 8 (interference). The standard score is 6.0. Figure 1 shows the correct answer obtained during pretest before reading in session 1, 2, 3 and 4 (baseline) as well as in session 5, 6, 7 and 8 (interference). The blue line showed the correct answer given by $\mathrm{F}$ and the red line showed the correct answer given by $\mathrm{M}$.

Figure 2 illustrates the acquisition of correct answers on a worksheet students' reading ability in learning sessions 1, 2, 3 and 4 and intervention at the session 5, 6, 7 and 8 . The blue line showed the correct answer given by $\mathrm{F}$, while the red one showed the correct answer given by M. Figure 3 describes the correct answer obtained from Student's Worksheet of Memorizing on session 1, 2, 3 and 4 (Baseline) as well as on session 5, 6, 7, and 8 (Interference). The correct answer given by F shown by the blue line, while the red one showed the correct answer given by $\mathrm{M}$.

Figure 4 shows the correct answer obtained during posttest. The blue line described the correct answer given by F, while the red one described the correct answer given by M. Figure 5 shows conclusion of the above results. That result showed the final score obtained.

Findings of the research stated that children with intellectual disability should be assisted by multimedia to illustrate the reading. It helps them to understand the reading content. As the case experienced by F. She was weak in reading and without illustrations it would not help her to understand the content. Besides, her eyes were also minus. Thus, F's eyes were easily tired. It was different with M. M experienced obstacle in concentrating. His attention was easily distracted (he loves to chat with his friend). Therefore, he needs to read several times in order to understand the content. Both cases showed that the data on the baseline (A) was still weak. It is evident from the results of the student's worksheet on reading skills which could not reached the minimum score set i.e. 6.0.

Table 1 is the table of final score acquisition of the correct answers on reading skills and memorizing. Thus, the value derived from the results of a pretest and a posttest in session 1, 2, 3 and 4 functioned as the "baseline". While in session 5, 6, 7 and 8 functioned as the "interference". As a comparison, let's take a look at the $1 \mathrm{st}$ session. Out of the 10 questions given on pretest, 3 correct answers were given by $\mathrm{F}$, while $\mathrm{M}$ answered 4 correctly. In the second session, $\mathrm{F}$ answered 5 correctly while $\mathrm{M}$ answered 6 . Then in the 3 rd session, $\mathrm{F}$ answered 5 correctly while $\mathrm{M}$ answered 4 , and for the 4th session, $F$ answered 6 correctly while $M$ answered 5. 
Short Paper-The Effectiveness of Multimedia in Education for Special Education (MESE) to Improve...

Table 1. Data obtained during A-B stage

\begin{tabular}{|c|c|c|c|c|c|c|c|}
\hline \multirow{2}{*}{ Baseline } & \multirow{2}{*}{ Sess. } & \multirow{2}{*}{ Name } & \multicolumn{4}{|c|}{ Number of correct answer } & \multirow[t]{2}{*}{ Final score } \\
\hline & & & Pretest & $S W$ of $R A$ & $S W$ of $M$ & Posttest & \\
\hline \multirow{8}{*}{ A } & \multirow{2}{*}{1} & $\mathrm{~F}$ & 3 & 6 & 4 & 6 & 4,75 \\
\hline & & $\mathrm{M}$ & 4 & 3 & 6 & 5 & 4,5 \\
\hline & \multirow{2}{*}{2} & $\mathrm{~F}$ & 5 & 5 & 6 & 6 & 5,5 \\
\hline & & $\mathrm{M}$ & 6 & 6 & 4 & 5 & 5,25 \\
\hline & \multirow{2}{*}{3} & $\mathrm{~F}$ & 5 & 5 & 4 & 5 & 4,75 \\
\hline & & $\mathrm{M}$ & 4 & 6 & 6 & 6 & 5,5 \\
\hline & \multirow{2}{*}{4} & $\mathrm{~F}$ & 6 & 3 & 6 & 5 & 5 \\
\hline & & $\mathrm{M}$ & 5 & 5 & 4 & 5 & 4,75 \\
\hline \multirow{2}{*}{ Interference } & \multirow{2}{*}{ Sess. } & \multirow{2}{*}{ Name } & \multicolumn{4}{|c|}{ Number of correct answer } & Final Score \\
\hline & & & Pretest & $S W$ of $R A$ & SW of $M$ & Posttest & \\
\hline \multirow{8}{*}{ B } & \multirow{2}{*}{5} & $\mathrm{~F}$ & 8 & 8 & 7 & 8 & 7,75 \\
\hline & & $\mathrm{M}$ & 7 & 7 & 7 & 8 & 7,25 \\
\hline & \multirow{2}{*}{6} & $\mathrm{~F}$ & 8 & 7 & 8 & 8 & 7,75 \\
\hline & & $\mathrm{M}$ & 8 & 8 & 7 & 7 & 7,5 \\
\hline & \multirow{2}{*}{7} & $\mathrm{~F}$ & 8 & 8 & 7 & 8 & 7,75 \\
\hline & & M & 7 & 8 & 8 & 8 & 7,75 \\
\hline & \multirow{2}{*}{8} & $\mathrm{~F}$ & 7 & 7 & 8 & 8 & 7,5 \\
\hline & & $\mathrm{M}$ & 8 & 4 & 8 & 7 & 6,75 \\
\hline
\end{tabular}

Note:

Sess.: Session

SW of RA: Student's Worksheet of Reading Ability

SW of M: Student's Worksheet of Memorizing

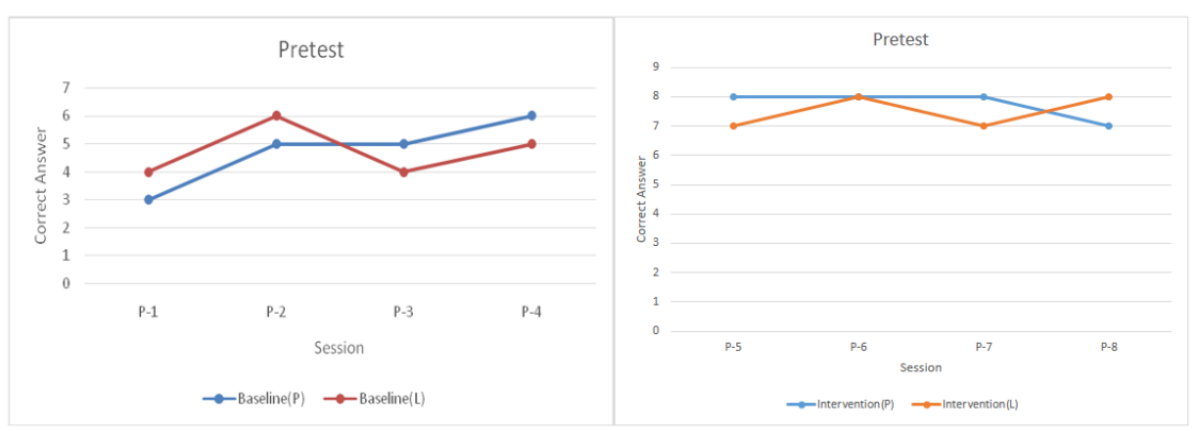

Fig. 1. Correct answer obtained during Pretest 


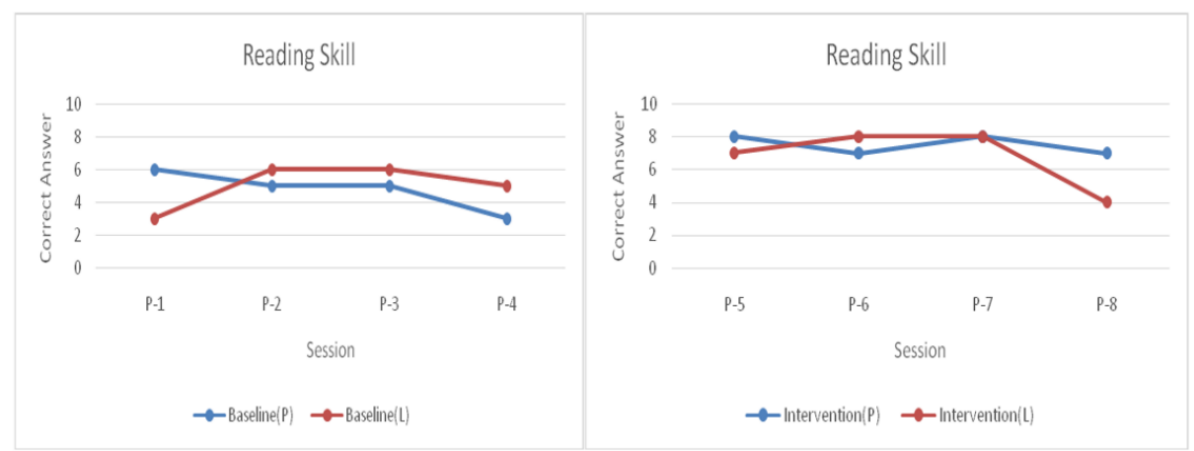

Fig. 2. The correct answer obtained from student's worksheet of reading ability

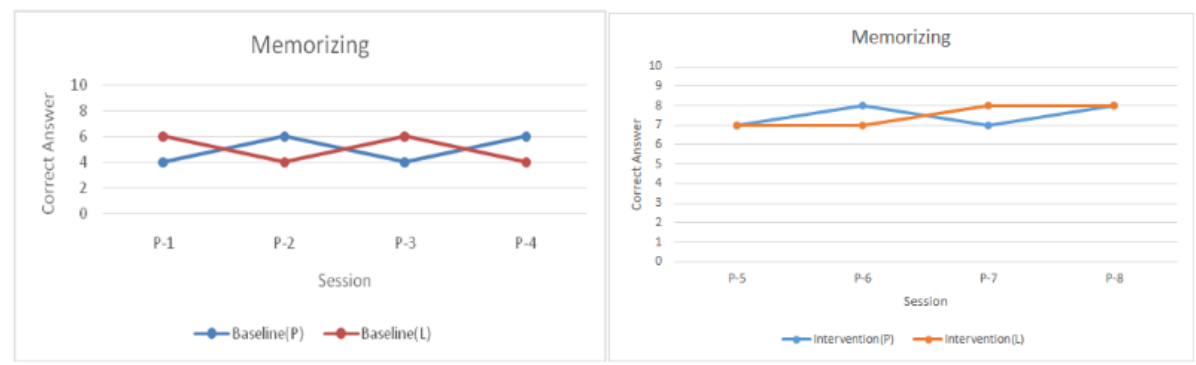

Fig. 3. The correct answer obtained from student's worksheet of memorizing

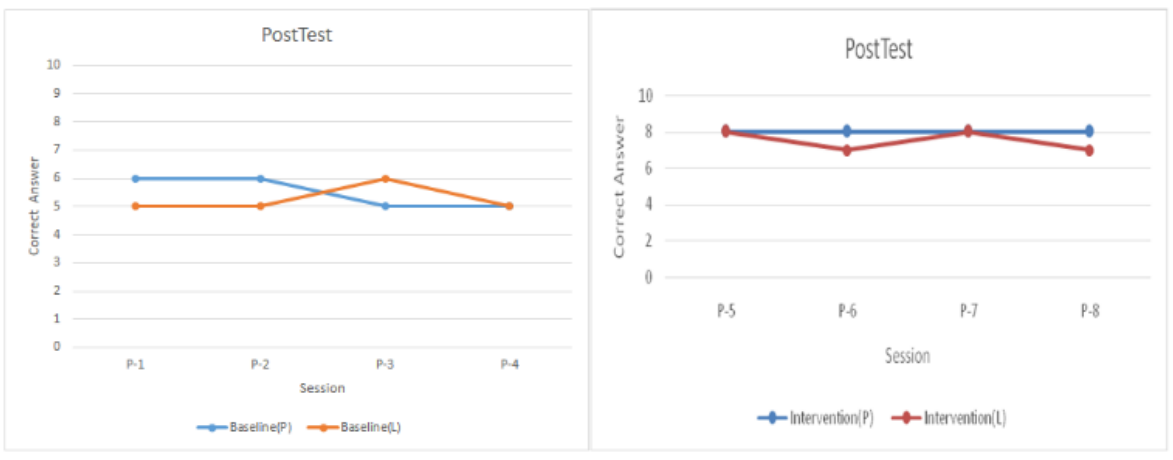

Fig. 4. The correct answer obtained during posttest 


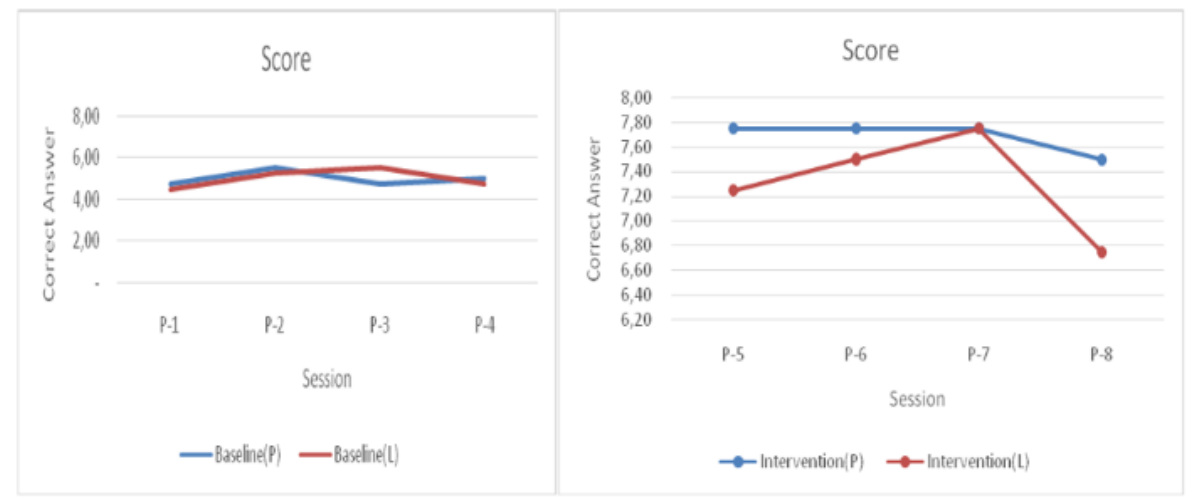

Fig. 5. The final score obtained

During 4 sessions, the student's worksheet showed unstable results. The student's worksheet of reading ability on session 1, 2, 3 and 4 showed that $F$ answered 6.5.5.3 correctly, while $\mathrm{M}$ answered 3.6.6.5. As for memorizing, on session 1, 2, 3 and $4 \mathrm{~F}$ answered 4.6.4.6 correctly, while $\mathrm{M}$ answered 6.4.6.4. In the post test, on session 1, 2, 3, and $4 \mathrm{~F}$ answered 6.6.6.5 correctly, while $\mathrm{M}$ answered 5.5.6.5. As for the final score obtained from session $1,2,3$ and 4 , F received point $4.75 ; 5.5 ; 4.75 ; 5$ while $\mathrm{M}$ $4.5 ; 5.25 ; 5.5 ; 4.75$. Thus, the baseline (A) concluded that both children were still not reached the minimum score set (6.0). Therefore, an interference by using MESE is needed to be able to understand the reading content and memorize.

The interference result shows the improvement of reading skills and memorizing. The data of pretest in session 5, 6, 7 and 8 given by $F$ is 8.8 .7 .8 , while $M$ answered 7.8.7.8. The results of the second pretest, both showed a good consistent result i.e. 7 and 8. For the student's worksheet of reading ability on session 5, 6, 7 and 8, F answered 8.7.8.7 correctly, while $\mathrm{M}$ answered 7.8.8.4. As for memorizing, in session 5, 6, 7 and 8, $\mathrm{F}$ answered 7.8.7.8, while $\mathrm{M}$ answered 7.7.8.8.

The post test results on session $5,6,7$ and 8 given by $F$ were 8.8.8.8 while $\mathrm{L}$ answered 8.7.8.7. As for the final score obtained on the session 5, 6, 7 and 8, F scores were $7.75 ; 7.75 ; 7.75$; and 7.50 , while $M$ scores were $7.25 ; 7.50 ; 7.75$; and 6.75 . The interference (B) concluded that both children fulfilled the minimum score set (6.0) though some cases in a particular session show no consistency especially in M's case on sessions 7 and 8 . From 8 correct answers, it falls into 4 even though the memory level is in a position of 8 correct answer.

The previous research stated that audio is better to be used in learning alphabets and visual in learning sentences (Carney \& Levin, 2002). Learning alphabets will be easier by singing or hearing sounds since analyzing will not be needed. As for learning sentences, visual will be needed in order to analyze alphabets series in creating sentences. Besides, visual contributes the role to understand the sentences as well as the content. MESE not only includes auditory and visual media but also animation as well as interactive media. Thus, students learn by using all senses. The analysis of the student's worksheet of reading ability and memorizing showed positive though sever- 
al sessions showed a decline and or a stable. However, in general the result showed that both fulfilled the minimum score set (6.0).

To maximize the outcomes, monitoring and assisting by family members who do not have disabilities would be necessary. This is in line with the previous research results that family can be an important educational agent [1].

\section{Conclusion}

Learning for children with intellectual disability needs to be assisted with the use of various media involving various senses. MESE (Multimedia in Education for Special Education) is one of the applications used for learning to read. The results showed that participants achieve success in learning to read and memorizing after the lesson intervened by MESE.

\section{$6 \quad$ References}

[1] P. Benitez and C Domeniconi, "Use of a Computerized Reading and Writing Teaching Program for Families of Students with Intellectual Disabilities" (2016), pp.127-138. https://doi.org/10.1007/s40732-015-0158-8

[2] R. N. Carney and J. R. Levin, "Pictorial illustrations still improve students' learning from text”, Educational psychology review, 14(1), (2002), pp. 5-26. https://doi.org/10.1023/ A: 1013176309260

[3] F. B. Cavallini, "Mental retardation and reading rate: effects of precision teaching", Life Span and Disability 13(1), (2010), pp. 87-101.

[4] M. B. Coleman, R. A. Cherry, T. C. Moore, Y. Park, and D. F. Cihak, "Teaching sight words to elementary students with intellectual disability and autism: A comparison of teacher-directed versus computer-assisted simultaneous prompting", Intellectual and Developmental Disabilities, 53(3), (2015), pp. 196-210. https://doi.org/10.1352/1934-9556$\underline{53.3 .196}$

[5] S. L. DeVeney, L. Hoffman, and C. J. Cress, "Communication-based assessment of developmental age for young children with developmental disabilities", Journal of Speech, Language, and Hearing Research, 55(3), (2012), pp. 695-709. https://doi.org/10.1044/10924388(2011/10-0148)

[6] K. S. Goodman, "Whole-language research: Foundations and development", The Elementary School Journal, 90(2), (1989), pp. 207-221. https://doi.org/10.1086/461613

[7] L.-Y. Huang, "Learning to Read with the Whole Language Approach: The Teacher's View", English Language Teaching, vol. 7, no. 5, (2014). https://doi.org/10.5539/elt. v7n5p71

[8] W. Leahy and J. Sweller Cognitive load theory, modality of presentation and the transient information effect. Applied Cognitive Psychology, 25(6), (2011), pp. 943-951. https://doi.org/10.1002/acp.1787

[9] P. Ling, "The" whole language" theory and its application to the teaching of English reading", English Language Teaching, 5(3), (2012), pp. 147. https://doi.org/10.5539/ elt.v5n3p147 
[10] R. Low and J. Sweller, "The modality principle in multimedia learning”, The Cambridge Handbook of Multimedia Learning, Cambridge University Press, New York, (2005), pp. 147-158. https://doi.org/10.1017/CBO9780511816819.010

[11] R. E. Mayer, "The Cambridge handbook of multimedia learning", Cambridge university press, London, (2005). https://doi.org/10.1017/CBO9780511816819

[12] J. Michel, "Enhancing the ability of adults with mild students with cognitive disabilities to recognize facial expression of emotions", Walden University, Minnesota, (2013).

[13] Munir, "The use of multimedia learning resource sharing (MLRS) in developing sharing knowledge at schools", International Journal of Multimedia and Ubiquitious Enginering, 10(9), (2015), pp. 61-68. https://doi.org/10.14257/ijmue.2015.10.9.07

[14] Munir, J. Kusnendar and Rahmadhani, "Developing an effective multimedia in education for special education (MESE): An introduction to arithmetic", AIP Conference Proceedings, 1708(1), 050001, (2016). https://doi.org/10.1063/1.4941159

[15] J. Nabizadeh, S. Mohammad and R. Adel, "The importance of whole language approach in teaching english to intermediate iranian EFL learners", Theory and Practice in Language Studies, 1(11), (2011), pp. 1643-1654.

[16] E. A. Nowickin and J. D. Brown, "A kid way strategies for including classmates with learning or intellectual disabilities", Intellectual and Developmental Disabilities, 51(4), (2013), pp. 253-262. https://doi.org/10.1352/1934-9556-51.4.253

[17] D. Rohendi, "Developing MESE to improve reading skills for mental retardation children", International Conference on Science in Information Technology (ICSITech) IEEE. (2015), pp. 197-201.

[18] E. Sadjaah, "Pendidikan bahasa bagi anak-anak gangguan pendengaran dalam keluarga". Sang Grafika, Bandung, (2003).

[19] J.Schweppe and R. Rummer, "Long-term multimedia learning. Staging Knowledge and Experience: How to Take Advantage of Representational Technologies in Education and Training”, (2012), pp. 196-198.

[20] P. L. Wang, "The effect of computer-assisted whole language instruction on Taiwanese university students' English learning”, English Language Teaching, 4(4), (2011), pp.10. https://doi.org/10.5539/elt.v4n4p10

[21] A. Ypsilanti, A. B. Vivas, T. R. äisänen, M. Viitala, T. Ijäs and D. Ropes, “Are serious video games something more than a game? A review on the effectiveness of serious games to facilitate intergenerational learning", Education and Information Technologies, 19(3). (2014), pp. 515-529. https://doi.org/10.1007/s10639-014-9325-9

\section{Authors}

Munir is currently a Professor of Computer Science, Faculty of Mathematics and Sciences Education, Universitas Pendidikan Indonesia. He received a Ph.D degree in Information Science from Universiti Kebangsaan Malaysia in 2001 on -Multimedia in Education for Literacy. Prof. Munir's research interests are in Multimedia for Education, ICT for Education and e-learning.

Wawan Setiawan is Professor of Computer Science, Faculty of Mathematics and Sciences Education, Universitas Pendidikan Indonesia. Researches interest include Computational Intelligence, Image Processing, and Education.

Eddy Prasetyo Nugroho is a lecturer of Computer Science, Faculty of Mathematics and Science Education, Universitas Pendidikan Indonesia (UPI), Indonesia. He 
graduated from STT Telkom Bandung in 2000 in the field of Informatics Engineering and obtained his master degree of Informatics at Institute of Technology, Bandung in 2005. His interests are Computer networks, Cryptography, and software Engineering.

Jajang Kusnendar is a lecturer of Computer Science, Faculty of Mathematics and Science Education, Universitas Pendidikan Indonesia (UPI), Indonesia. He graduated from Institut Teknologi Bandung in 2004. His interests are Algorithm and Programming, software Engineering.

Aji Prasetya Wibawa, is a lecturer in department of electrical engineering, Universitas Negeri Malang (UM). He have achieved his PhD electrical and information engineering from University of south Australia (UniSA). His research interest are natural language processing, machine translation, intelligent tutoring systems and social informatics.

Article submitted 23 January 2018. Resubmitted 11 April 2018. Final acceptance 23 June 2018. Final version published as submitted by the authors. 